\title{
The Application of Autonomous Learning in English Phonetics Teaching
}

\author{
Wang Xin ${ }^{1}$ \\ ${ }^{1}$ Liaoning Vocational and Technical College of Mechanical and Electrical Engineering, Dandong, \\ Liaoning, China , 118009 \\ a email
}

Key words: Autonomous Learning; English Phonetics; Application

\begin{abstract}
Since the 1980s, the education sector has studied autonomy learning from different perspectives. Autonomous learning is not only the goal of the course, but also learning methods and learning ability, not only can effectively improve academic performance, but also lay the foundation for lifelong learning. In the process of English learning, pronunciation is the carrier of spoken language, which plays an important role in cultivating students' comprehensive English skills. This paper applies the concept of autonomous learning to the teaching of English phonetics. It expounds the connotation and influencing factors of autonomous learning and studies the effective combination and application strategies of autonomous students and English phonetics teaching. It stimulates students' initiative in learning phonetics, and enhances students' cooperative learning and autonomous learning ability, also can effectively improve the level of English teaching.
\end{abstract}

\section{Introduction}

Phonetics, grammar and vocabulary are the three elements of English, and occupy an important position in English learning. English involves listening and speaking skills, including phonetics as the basic unit, words, sentences and articles. Therefore, the students' phonological ability is directly related to their spoken language and hearing level. Many English teaching theories only pay attention to grammar and vocabulary, but ignore the phonetic teaching, only superficial learning phonetics, not in-depth study of links among phonetic, sentence and vocabulary, which is difficult to help students master liaison, weak tone, stress and other pronunciation skills, resulting the ability of students to read, write and speak communication. In recent years, China's education sector indepth study of language learning strategies and learning process, put forward the importance of the dominant position of students, and cultivate students' self-learning ability is an important English teaching objectives. Facing the status quo of English phonetics teaching, cultivating students' ability of autonomous learning, can effectively improve the quality of phonetics teaching.

\section{The connotation and its influencing factors of autonomous learning}

Autonomous learning is a modern learning concept and learning method, considering students as the core who are dominated by listening, reading, observation, research, practice, etc., so that students obtain sublimation and improvement in the value and emotion, process and methods, skills and knowledge.

First of all, the autonomous learning is a kind of the internal learning mechanism combined with learning strategies and students' learning ability and attitude and other factors, is also the ability of students to control and understand the autonomy of learning, such as the ability according to learning tasks to choose learning activities and learning methods, learning process, the ability to evaluate learning outcomes. Second, autonomous learning is the control ability for the students to choose learning materials, learning methods, learning content, learning objectives of control. In terms of learners, cultivating autonomous learning ability is to provide conditions and space for students to self-study, and to coordinate the relationship between macro-teaching objectives and students' autonomous students. Finally, autonomous learning is a learning mode, that is, a learning method for students in the overall teaching objectives management, under the guidance of teachers, 
in accordance with their own needs and actual conditions designed to achieve learning goals,which requires the school to provide learning conditions and students have independent learning ability.

In the study of autonomous learning and English phonetics teaching process, we should attach importance to the basic elements of curriculum design, also to analyze the factors that have a direct impact on the autonomy of learning, mainly including three factors. First, the teacher. Teachers are helpers and promoters who can help students to form self-study habits, to clear learning objectives, to develop learning programs and to establish learning self-confidence. At the same time, teachers can be a bridge for students to establish self-learning and classroom education, which can combine counseling students to classroom learning and self-learning. Secondly, learning style. On the cognitive level, many students accustomed to teachers or schools to develop learning objectives and learning plan, the external environment as the main basis for processing information, which is easy to have an impact. Students pay more attention to learning resources, and they need teachers to teach and guide, but their own learning style can not design their own learning goals, can only rely on the teaching objectives of teachers to adjust and develop learning objectives, so their abilities to cultivate self-learning has hindered. Finally, self-efficacy. In 1977, the American social learning theory founder, psychologist Brandura put forward self-efficacy theory. It is pointed out that in the human self-regulation system, the ability to judge their own plays an important role, indicating that the individual can not achieve the goal of their own ability and confidence. When students learn English pronunciation, because they do not trust their ability to develop low learning goals, and less confidence and tension, anxiety, have a greater impact on the quality of learning.

\section{The effective combination of autonomous learning and English phonetics teaching}

The combination of autonomous learning and English phonetics teaching is to help students meet the requirements of the times and competent future work attitude, habits and basic skills. Integration process is the process of student spirit and self-realization development, to help students to learn according to interest, better to tap their creativity and potential. At the same time, from the adjustment of learning content, teaching learning strategies, creating a learning environment, the establishment of the mentor mechanism to achieve an effective combination of independent learning and English speech teaching.

According to students' learning style, learning state to adjust course materials and organize phonetics teaching, and in accordance with students to select practice materials in the English classroom to help students understand and correct pronunciation problems in self-learning can quickly find strong targeted of the exercises. In addition, the choice of task-driven teaching methods can help students through mutual cooperation to achieve teaching objectives, and master the speaking skills.

Teachers want to achieve in the classroom each student with different methods of teaching ideas, the realization difficulty is particularly high, but independent learning make it possible that achieving personalized teaching methods and learning programs possible. However, teachers can not develop a detailed and comprehensive learning plan for each student, nor can they adjust the plan at any time because of students' problems. This is the fundamental reason for students to understand autonomous learning strategies and learning methods. In this premise, to enhance selflearning students is to carry out a sense of self-efficacy, thereby enhancing their learning quality and learning efficiency. Teachers should help students to understand the role and objectives of phonetic learning, but also show students that they already have venues and resources, such as autonomous phonetics learning resources, school reading room, library, etc., to enhance students' application skills and awareness.

First of all, we must gradually improve the school learning network, study room, library and other learning tools, to establish excellent independent learning platform. Second, the emphasis on students needs, self-reserved for their own learning sufficient time to improve their self-learning initiative. Third, the combination of the contents of the course arrangements for learning tasks to encourage and guide the cooperation, so that students become the object of learning each other. Finally, the expansion of teacher-student communication channels, both to ensure classroom 
teaching, also to network forums, practice guidance and other forms, to improve the communication between teachers and students, when students cope with self-learning tasks, you can seek tips and inspiration, rather than choose to give up and dependence on teachers.

In the course of designing English pronunciation, the school should abide by the basic principles of "bold reform, courage to explore; attach importance to results and monitor the process", break the shortcomings of traditional phonetic teaching mode, and carry out tutor grouping to correct and direct the quality and learning process of students' self- study.

\section{The application research of autonomous learning on English phonetics teaching}

Autonomous learning is not a static process, but with the learning experience of students to change. Teachers need to study, analyze students' ability in accordance with the curriculum, to develop students to help students learn English pronunciation teaching. To guide students to self-study, there are four stages.

Usually, in the first week of the semester, teachers and students sum up, reflect and review the shortcomings and gains of previous learning, explain the knowledge points through language cognitive strategies, analyze the reasons of gains and losses, and put forward the impact of autonomous learning and autonomy training on learning quality. For example, in summing up the last semester of learning process, some students summarize the intonation, such as the general question with the rise, and special questions, declarative sentences with the tone, but the communication and reading is difficult to correctly use the tone. The results show that some students do not have a clear understanding of the intonation unit, and they do not distinguish the difference between the tone unit and the stress word. Some of the students, after practicing their pronunciation, found that they lacked knowledge and applied knowledge points. At the same time, some students are just beginning to develop voice learning plan, but did not reflect, summarize and optimize the plan, the lack of strong independent learning ability. Through the analysis of teachers and students of independent learning, it can help students understand the status quo of learning, improve self-learning ability of speech, enhance learning concepts, and lay the foundation for future learning.

Extracurricular self-learning and classroom teaching are organic whole and need the cooperation of teachers and students. Therefore, teachers of English phonetics teaching scientific planning can promote students to carry out self-learning.

First of all, we should help students to establish the goal of learning English pronunciation and select the learning content, so that more independent learning has personalized features. In order to complete the teaching requirements, teaching objectives and teaching contents stipulated in English syllabus, and to help form the consciousness of autonomous learning, teachers and students review the learning experience before studying the textbook structure and knowledge composition of phonetic system.

Secondly, the teacher will introduce the learning plan to the students, and develop self-learning plan, based on autonomous learning to complete the requirements of classroom teaching. English phonetics teaching includes learning system knowledge and practice. It adopts classroom interaction, communication demonstration, language practice and group teaching to achieve teaching objectives. Therefore, students should develop personalized learning plan, and record the daily learning process for teachers teaching and after-school counseling, adjustment and assessment of students to provide learning basis for learning plans. Students through the teachers, networks, textbooks and other resources to learn new knowledge to solve new problems.

The implementation of English phonetics teaching, it is necessary to provide students with independent learning space, but also supervision and guidance of self-learning. Students in the extra-curricular learning programs in accordance with their own voice of independent learning, teachers should build a counseling platform, such as school counseling time, network mailbox, QQ group, through student learning diary, to keep abreast of student learning to guide their learning doubt. classroom, combined with phonetic practice and group learning situation, using phonetic theory of knowledge to correct pronunciation errors, additional knowledge, evaluation of learning 
quality, and self-learning guidance and feedback. Teachers at this stage should be learning process supervision and guidance, while students fully demonstrate the main role, and complete the extracurricular self-learning and classroom teaching together to finish the cognitive strategy of speech. Autonomous learning can solve the problem of short practice time, classroom practice and theoretical learning for teachers to obtain opportunities of supervision and guidance of selflearning, so phonetics teaching in student cooperation, teachers and students can achieve the use and sharing of resources.

Evaluation is an important part of the implementation of teaching planning. Because the English pronunciation teaching is according to the student independent study, the actual situation as well as the syllabus request. Therefore, the evaluation should summarize and reflect on the theoretical knowledge of teaching and learning, learning quality and practice process, to select the learning diary, voice test, questionnaire and other methods to carry out students assessment, and then to stimulate student autonomy and teachers teaching enthusiasm. It is necessary to evaluate students' phonological effects and autonomous learning ability according to their needs, so that students can get the evaluation results in time. It can help them to form the concept of autonomous learning, and effectively enhance their autonomous learning ability. In addition, it is necessary to promote teachers to reflect and gradually improve the teaching design, enhance teaching quality. Assessment should be the systematic and coherent, in accordance with the teaching content to establish a subtype assessment and summary assessment. In the teaching of phonetics, the teaching, learning and knowledge construction are evaluated on the premise of intonation, rhythm and phoneme, and the teaching outlook is evaluated.

\section{Conclusion}

Teaching students how to learn is the main purpose of modern teaching reform. Modern cognitive psychology Pointed that the process of learning to understand the control methods and strategies are learning the connotation and nature. The application of autonomous learning in English phonetics teaching, leading learners to study independently. In the lack of autonomy ability of students, the teacher should play a role of counselors and supervisors. At the same time, teachers should analyze the actual situation of learners, such as the level of English pronunciation of students, personality, etc., to provide differentiated guidance for different students, so that each student in the study can be harvested.

\section{Acknowledgements}

Fund Project: 2016 Liaoning Vocational and Technical College of Mechanical and Electrical College-level Teaching and Research Topic. The results of the stage of "English Pronunciation" Elective Course Set Research and Practice". The subject approval number: JYLX2016039. Moderator: Wang Xin.

\section{References:}

[1] Liu Chenjun. Autonomous Learning Theory and College English Pronunciation Teaching [J]. Asia-Pacific Education, 2016,01: 162.

[2] Liu Ying. Contracted Autonomous Learning Theory in English Large Class Teaching [J]. Journal of Zunyi Normal University, 2016, 02: 123-127.

[3] Xing Xing. English Autonomous Learning Platform in the Role and Application of College English Teaching [J]. China Training, 2016,10: 294 